\title{
Optimisation of Compressed Air Assisted-Turning-Burnishing Process for Improving Machining Quality, Energy Reduction and Cost-effectiveness
}

\author{
Trung-Thanh Nguyen ${ }^{1}$ and Chi-Hieu Le ${ }^{2}$
}

${ }^{1}$ Faculty of Mechanical Engineering, Le Quy Don Technical University, 236 Hoang Quoc

Viet, Ha Noi 100000, Viet Nam.

${ }^{2}$ Faculty of Engineering \& Science, University of Greenwich, Chatham ME4 4TB, UK.

\begin{abstract}
:
The burnishing process is used to enhance the machining quality via improving the surface finish, surface hardness, wear-resistance, fatigue and corrosion resistance, and it is mostly used in aerospace, biomedical, and automotive industries to improve reliability and performance of the component. The combined turning and burnishing process is therefore considered as the effective solution to enhance both machining quality and productivity. However, this leads to the complexity and challenges for selection of the right machining parameters. Therefore, the trade-off analysis between energy consumption, surface characteristics, and production costs has not been well-addressed and investigated. This study presents an optimisation of the compressed air assisted-turning-burnishing (CATB) process for aluminum alloy 6061, aimed to decrease the energy consumption and surface roughness, and to enhance the Vicker hardness of the machined surface. The machining parameters for consideration include the machining speed, feed rate, depth of cut, burnishing force, and the ball diameter. The improved Kriging models were used to construct the relations between machining parameters and technological response characteristics of the machined surface. The optimal machining parameters were obtained utilising the desirability approach. The energy based-cost model was developed to assess the effectiveness of the proposed CATB process. The findings showed that the selected optimal outcomes of the depth of cut, burnishing force, diameter, feed rate, and machining speed are $0.66 \mathrm{~mm}, 196.3 \mathrm{~N}, 8.0 \mathrm{~mm}, 0.112 \mathrm{~mm} / \mathrm{rev}$, and $110.0 \mathrm{~m} / \mathrm{min}$, respectively. The energy consumption and surface roughness are decreased by $20.15 \%$ and $65.38 \%$, respectively, while the surface hardness is improved by $30.05 \%$. The production cost is decreased by $17.19 \%$ at the optimal solution. Finally, the proposed CATB process shows a great potential to replace the traditional techniques which are used to machine non-ferrous metals.
\end{abstract}

Keywords: Turning; Burnishing; Energy; Roughness; Hardness; Optimisation; Kriging; Desirability. 


\section{Introduction}

Improving energy reduction, machining quality, machining efficiency and productivity as well as minimising production costs are the primary purposes of businesses to maximize profits and impacts, and to increase sustainability performance. In order to enhance quality of manufacturing processes and increase industrial productivity, efficiency and sustainable impacts, fundamentally, there are two approaches which are commonly applicable in practices. The first approach is to optimize manufacturing processes and work-flows. The second approach is to enhance efficiency and capability of manufacturing systems with new technologies and resources. The first approach should be done first, and it is considered as the cost-effective solution in both technical and economic aspects, in which manufacturing operations and work-flows are optimally controlled and managed with the right technical parameters and solutions, within the constraints of technologies and manufacturing sources. The second approach require more effort and investments, since new machines and equipment of more advanced technologies need to be invested, and new human and manufacturing resources may also need to be enhanced.

The burnishing process is used to enhance the machining quality via improving the surface finish, surface hardness, wear-resistance, fatigue and corrosion resistance, and it is mostly used in aerospace, biomedical, and automotive industries to improve reliability and performance of the component. The combined turning and burnishing process is therefore considered as the effective solution to enhance both machining quality and productivity. However, this leads to the complexity and challenges for selection of the right machining parameters.

The optimal selection of technical parameters for enhancing technological response characteristics of a single manufacturing process has been addressed and well-documented [14]. The variety of specific cutting energy (SCE) for the orthogonal turning of Al 6061-T6 alloy was considered using a novel mapping approach [1], in which the considered technical parameters were the feed rate $(f)$ and machining speed $(v)$. It was concluded that the feed rate was the most effective parameter for reduction of energy consumption, followed by the cutting speed; and the consumed energy was decreased by $27 \%$ per each kilogram of removed material. An energy map for the high-speed machining of Al 6061-T6 alloy was proposed to identify the most energy-efficient parameters; it was stated that the lowest energy could be obtained at a cutting speed of $1500 \mathrm{~m} / \mathrm{min}$, and the energy consumed could be saved around $47 \%$ at the optimal solution [2]. An attempt was made to decrease the SCE as well as the surface roughness (SR) and improve the material removal rate (MRR) for the high-speed turning of Al $6061 \mathrm{~T} 6$ alloy [3], in which the grey relation analysis (GRA), analytic hierarchy 
process (AHP), and response surface method (RSM) were used to select optimal parameters. The outcomes of [3] revealed that (1) the improvements in the SCE and MRR were 5\% and $33 \%$, respectively, while the SR remained unaffected; and (2) the depth of cut (a) of $3 \mathrm{~mm}$, the $f$ of $0.3 \mathrm{~mm} / \mathrm{rev}$., and the $v$ of $1500 \mathrm{~m} / \mathrm{min}$ were listed as optimal parameters. The interpolative models of the SCE, arithmetical mean roughness $\left(\mathrm{R}_{\mathrm{a}}\right)$, and means roughness depth $\left(\mathrm{R}_{\mathrm{z}}\right)$ were developed in terms of the spindle speed $(S)$, nose radius $(r), f$, and $a$ for the dry milling of SKD61 material [4]; and the findings showed that a set of feasible optimal solutions could be employed to obtain a low SCE, a smooth surface, and high MRR. The artificial neural network (ANN) was applied to develop the models of the machining force $\left(\mathrm{F}_{\mathrm{c}}\right)$ and SR regarding the axial depth of cut $\left(a_{\mathrm{p}}\right), v$, and $f$ for the milling of Inconel 738 [5]; and it was stated that the ANN models were useful for the prediction of technological response characteristics of machining process (machining responses); and the optimal values of the $v, f$, and $a_{p}$ were $45 \mathrm{~m} / \mathrm{min}, 0.15 \mathrm{~mm} /$ tooth, $0.1 \mathrm{~mm}$, respectively.

The optimal machining parameters $v, a, f$, and $r$ were selected to obtain the improvements in the power factor (PF), energy consumption (EC), and SR for the dry machining of a stainless steel 304 [6]; and the results indicated that EC and SR were decreased by $34.85 \%$ and $57.65 \%$, respectively, while the PF was enhanced by $28.83 \%$. Laouissi et al. (2019) proposed the solutions to predict the tangential cutting force $\left(\mathrm{F}_{\mathrm{z}}\right)$, cutting power $\left(\mathrm{P}_{c}\right)$, the MRR, and SR for the turning process of the cast iron, based on the ANN and RSM models [7]; and the authors emphasized that the ANN model could be applied to provide higher precision, as compared to the RSM one. Awale et al. (2020) applied the GRA model to obtain the improvements in the machining force $\left(\mathrm{F}_{\mathrm{c}}\right)$, machining temperature (MT), SR, and MRR [8]; and the outcomes indicated that the optimal values of the $r, v, f$, and $a$ were $1.2 \mathrm{~mm}, 450 \mathrm{~m} / \mathrm{min}, 0.05 \mathrm{~mm} / \mathrm{rev}$, and $0.2 \mathrm{~mm}$, respectively. Nguyen et al. (2020) applied the adaptive neuro-fuzzy inference system (ANFIS) to show the relations between the machining rate (MR), EC, and $\mathrm{R}_{\mathrm{a}}$ in terms of the inclination angle $(\alpha), \mathrm{a}, \mathrm{f}$, and $\mathrm{v}$ for the rotary turning [9], in which the adaptive simulated annealing (ASA) was used to select the optimal outcomes; and the authors stated that the EC and $\mathrm{R}_{\mathrm{a}}$ were reduced by $50.29 \%$ and $19.77 \%$, while the MR was improved by $33.16 \%$, respectively. The assessment of the sustainable indicators, including energy efficiency $(\mathrm{EF})$, turning cost $\left(\mathrm{T}_{\mathrm{c}}\right)$, operational safety (OPS), and $\mathrm{R}_{\mathrm{a}}$ for the rotary tuning were conducted by Nguyen et al. (2020) [10], in which the neighborhood cultivation genetic algorithm (NCGA) was applied to identify the optimal parameters; and the results showed that the improvement in the EF was by $8.91 \%$, while the $\mathrm{R}_{\mathrm{a}}$ and $\mathrm{T}_{\mathrm{c}}$ were decreased by $20.00 \%$ and $14.75 \%$, respectively at the optimal solution. 
The impacts of the blunt and edge of the micro-textured tool on the MF and MT in the milling titanium alloy have been explored by Tong et al. (2020) [11], in which the optimal geometric characteristic was selected using the support vector regression and genetic algorithm; and the authors stated that the enhancements in the tool life (TL) and SR were 33\% and $26 \%$, respectively with the aid of the optimal micro-textured tool. Alswat et al. (2020) proposed a new energy model to identify optimal values for machining parameters of turning operations, taking into account the energy footprint, the cutting tool utilization and the material removed volume [12], in which a case study was employed to validate the effectiveness of the proposed approach; and the results showed that the proposed model was effectively applied to generate reliable machining parameters, as compared to traditional ones. The influences of the $\mathrm{f}, \mathrm{v}$, and a on the SCE, SR, and TL of the turning of Ti-6Al-4V were investigated by Khan et al. (2019) [13], in which different cooling conditions, including the dry, wet, and cryogenic were considered; and the authors stated that the TL, SCE, and SR were improved by $33 \%, 10 \%$, and $9 \%$, respectively, with the aid of the cryogenic machining. Similarly, the variety of the SCE under different cutting conditions including dry, wet, and cryogenic for the turning aerospace alloy Ti-6Al-4V were investigated by Khan et al. (2020) [14]; and the results revealed that the SCE at the cryogenic machining was decreased by $9 \%$ and $16 \%$, as compared to the dry and wet cuttings, respectively.

Recently, different hybrid processes have been developed to enhance the machining responses, including energy efficiency, machining quality, productivity, production costs. Especially, various machining techniques were proposed to machine cylindrical workpieces. The effects of the sequential turning and burnishing process on surface topography, compressive stress (CS), micro-hardness $(\mathrm{MH})$, porosity content $(\mathrm{PC})$, and bonding strength (BS) of the Cr-Ni steel cladding were systematically investigated by Zhang and Liu (2015) [15]; and the findings revealed that (1) the machining responses were improved with the support of the sequential burnishing process; and (2) the PC and BS of the cladding layer were enhanced with the aid of the CS. A novel sequential process incorporating the hard turning with low plasticity burnishing was developed to enhance the surface integrity and corrosion resistance of $\mathrm{Cr}-\mathrm{Ni}$ alloys [16]; and the authors stated that the $\mathrm{CS}$ and surface finish have important roles in improving the corrosion resistance; and the integrative process could be applied to produce anti-corrosion components. Hua et al. (2019) developed a hybrid operation comprising the finish turning and low plasticity burnishing to improve the surface integrity and fatigue characteristic of Inconel 718 [17]; the results showed that (1) the surface characteristics, including the topography, phase change, MH, CS, and SR were significantly improved, (2) the fatigue life can be enhanced by $82.4 \%$ with the aid of a hybrid approach, 
and (3) the fatigue life was primarily affected on the CS and SR. An integrative operation using the turning and roller burnishing was developed to machine the long shafts [18], in which the mathematical model of the SR was developed in terms of the slenderness of shaft $(S S)$, burnishing force $(B F), f$, and $S$; and the results showed that (1) the $\mathrm{f}$ is the most effective parameter, followed by the $B F, S S$, and $S$, respectively; and (2) the hardness, residual stress, wear resistance, and fatigue strength of machined components were improved with the support of the proposed process.

Mezlini et al. (2014) developed a new hybrid tool using a calibrating spring to enhance the surface properties of the cylindrical sample [19], in which the influences of the burnishing pressure $(p), f$, and $v$ on the total machining time ( $\left.\mathrm{T}_{\text {total }}\right)$ and SR were considered; and the results indicated that the improvements in the SR and $\mathrm{T}_{\text {total }}$ were decreased by $77 \%$ and $51 \%$, respectively. The behavior of the CS of the turning-burnishing was investigated under the variety of the $B F, f, v$ with the aid of a simulation model [20]; and the findings showed that there are small errors between the predicted and experimental values, and the model accuracy was therefore acceptable. Rami et al. (2018) investigated the optimal outcomes of the $v, f, B F, D$, and $a$ to enhance the $\mathrm{MH}, \mathrm{SR}$, and CS for the turning-burnishing process of AISI 4140 steel [21]; and the author stated that the technical parameters were enhanced, in which the SR is improved by $70 \%$.

The above presented reviews showed that different machining solutions and models have been developed to enhance the surface quality of machined workpieces, reduce the production cost, and miminise the energy consumption. However, there are two identified challenges which can be listed as follows:

(1) Challenge 1: The parameter-based energy optimisation of the turning-burnishing operation has not considered in the aforementioned works. The performance model expressing the relation between the machining conditions and energy consumed has not proposed for the selection of optimal parameters. Higher energy efficiency, low carbon emissions, low manufacturing costs are the urgently growing demands, especially when considering issues related to the global warming and the increase of energy consumptions and cost.

(2) Challenge 2: The regression models, such as the linear and second-order formulations were widely applied to depict the relations between the processing inputs and machining parameters in the optimisation models. Unfortunately, these approaches result in a low predictive accuracy due to the approximate behavior [22]. Therefore, it is necessary to investigate higher accurate models for optimisation of the turning-burnishing process. 
This work presents an optimisation of a new hybrid process of machining the aluminum alloy 6061, with solutions to overcome the above identified challenges, with the focus on reducing the energy consumption and enhancing the quality of the machined surfaces, especially the surface roughness and hardness. The compressed air assisted-turningburnishing (CATB) operation were developed to machine the cylindrical workpieces, in which a new hybrid device was successfully designed and fabricated. The technological response characteristics include the energy consumed in the turning-burnishing stage $\left(\mathrm{E}_{\mathrm{M}}\right)$, surface roughness (SR), and Vicker hardness $(\mathrm{VH})$. The processing inputs are the machining speed $(v)$, feed rate $(f)$, depth of cut $(a)$, burnishing force $(B F)$, and the diameter of the burnishing ball $(D)$. The relations between the experimental conditions and the machining responses of the CATB process are developed using the Kriging models. And the desirability approach (DA) is utilized to generate feasible solutions and determine the best design point.

\section{The compressed air assisted-turning-burnishing process}

\subsection{The compressed air assisted-turning-burnishing tool}

The compress air assisted-turning-burnishing tool was successfully designed and fabricated, as shown in Fig. 1. The structure of the hybrid tool was designed so that it is easily and conveniently assembled on the universal computer numerical controlled (CNC) lathes. With the use of the compress air assisted-turning-burnishing tool, the turning and burnishing operations are combined in one single machining process. The turning insert is a set ahead of the burnishing ball; hence, the turning and burnishing operation are performed on the same path. Moreover, the chips are avoided and they are entangled or pressed on the machined surface with the aid of this compress air assisted-turning-burnishing tool.

The primary components include the turning tool, the base, the holder, pneumatic cylinder, position bolts, and burnishing head. The turning and burnishing tools are rigidly held in the base. The turning tool with the replaceable insert and shank are clamped on the base mount. The carbide insert labeled CCGT09T302-AZ is mounted on the turning tool shank SCLCR1616H09. The technical data of the turning insert and shank are shown in Figs. 2a and $\mathrm{b}$, respectively. Three-position bolts are employed to firmly hold the turning tool in a certain position. The turning tool can be adjusted in both forward and backward directions when the bolts are loosened. The base is installed in the tool-turret of the lathe machine.

The pneumatic cylinder with the burnishing head is clamped on the cylindrical surface of the holder. Two-position bolts are employed to firmly clamp the pneumatic cylinder in a certain position. The forward or backward motions of the air cylinder are adjusted when the bolts are loosened. The motion of the piston rod is controlled with the aid of the rod and capend ports. The burnishing head is assembled with the piston rod using a threaded joint. The 
burnishing head comprises a burnishing ball and three support balls, which allows minimizing the friction. The hardness of $62 \mathrm{HRC}$ and roughness of $0.05 \mu \mathrm{m}$ are employed in the compressing ball.

The burnishing force is calculated as:

$$
B F=p_{o} A_{p}
$$

where $\mathrm{p}_{\mathrm{o}}$ and $\mathrm{A}_{\mathrm{p}}$ denote the operating pressure (MPa) and pressure area $\left(\mathrm{mm}^{2}\right)$.

With the proposed design, the turning tool and burnishing ball can be easily replaced with different shapes and/or dimensions, and the proposed compressed air assisted-turningburnishing tool can be used to perform different operations, including turning, burnishing, and turning-burnishing for a cylindrical workpiece.

\subsection{The operating principle of the compressed air assisted-turning-burnishing process}

The operating principle of the compressed air assisted-turning-burnishing process is shown in Fig. 3. A pneumatic pump is used to generate compressed air in the preparation stage. The pressure value is detected using the gauge. The motion direction of the piston rod is changed using a solenoid valve. The motion forward of the piston rod is performed when the compressed air enters the cap-end port. After the machining period, the piston rod is moved back to the original position when the compressed air enters the rod-end port. The flexibility of the compressed air allows it more convenient to adjust the burnishing force for a specific purpose.

\section{Optimisation framework}

\subsection{Optimisation issues}

The energy consumption in the CATB process $\left(\mathrm{E}_{\text {total }}\right)$ can be divided into four primary components, including the start-up energy $\left(E_{s t}\right)$, standby energy $\left(E_{s b}\right)$, air machining energy ( $\left.E_{a i r}\right)$, and turning-burnishing energy $\left(E_{M}\right)$, as shown in Fig. 4. The total energy of the CATB process can be calculated as:

$$
E_{\text {total }}=E_{s t}+E_{s b}+E_{\text {air }}+E_{m}=P_{s t} t_{s t}+P_{s b} t_{s b}+P_{\text {air }} t_{\text {air }}+P_{M} t_{M}
$$

where, $\mathrm{P}_{\mathrm{st}}, \mathrm{P}_{\mathrm{sb}}, \mathrm{P}_{\mathrm{air}}$, and $\mathrm{P}_{\mathrm{m}}$ denote the consumed powers in the start-up, standby, air machining, and turning-burnishing stages.

Practically, the values of energy consumed in the start-up, standby, and air machining times can be considered as constant values due to the less dependency on the varied parameters. Therefore, the energy used in the turning-burnishing stage is considered as the machining objective, which is expressed as:

$$
E_{M}=P_{M} t_{M}
$$

where, $\mathrm{P}_{M}$ and $\mathrm{t}_{\mathrm{M}}$ present the power consumed in turning-burnishing stage and turningburnishing time. 
The power consumed in turning-burnishing stage is expressed as:

$$
P_{M}=P_{\text {air }}+P_{T B}=P_{s b}+P_{\text {operational }}+P_{T B}
$$

where, $\mathrm{P}_{\text {operational }}$ presents the required operational power, which is expressed as:

$$
P_{\text {operational }}=k_{1} V^{2}+k_{2} V+k_{3}
$$

where, $\mathrm{k}_{1}, \mathrm{k}_{2}$, and $\mathrm{k}_{3}$-the experimental coefficients of the quadratic model.

The machining conditions for consideration are as follows: the characteristics of the turning insert (diameter, normal rake angle, and materials), the properties of the burnishing ball (diameter, hardness, and materials), the process parameters (machining speed, feed rate, depth of cut, and burnishing force), lubrication characteristics (dry, MQL, flood, and cryogenic), and the workpiece materials. The affecting parameters that are most likely to influence the consumed energy, surface roughness, surface hardness, and production costs are shown in Fig. 5 with the aid of the Ishikawa diagram.

In this study, the characteristics of the turning insert and workpiece are considered as constants. All machining tests are performed in the dry condition. Therefore, the machining speed, feed rate, depth of cut, burnishing force, and the diameter of burnishing ball are considered as the optimal inputs.

The machining parameters for considerations and their levels are presented in Table 1. The parameter ranges are selected based on the characteristics of the employed machined tool, turning insert, pneumatic cylinder, and they are verified with the literature review. The turning trials at the highest levels are conducted to ensure that the consumed power is less than the maximum power.

\subsection{Optimisation approach}

The systematic procedure for the selection of optimal inputs is shown in Fig. 6.

Step 1: The CATB trials are conducted in order to collect the necessary data.

Step 2: The Kriging models of the $\mathrm{E}_{\mathrm{M}}, \mathrm{SR}$, and VH are developed in terms of machining conditions. The Kriging model is an interpolative correlation using the Gaussian function, which can be expressed as [23]:

$$
y(\mathrm{x})=g(x)+z(x)
$$

where $g(x)$ and $z(x)$ denotes the global model and local deviation, respectively.

The distance between the $x_{i}$ and $x_{j}$ is computed as:

$$
d_{i}\left(x^{i}, x^{j}\right)=\sum_{n=1}^{m} \theta_{k}\left|x_{n}^{i}-x_{n}^{j}\right|^{2}
$$

where $\theta_{k}$ is the correlative factor of the $k_{t h}$ element.

The correlation between the $\mathrm{z}\left(x_{i}\right)$ and $\left(x_{j}\right)$ is calculated as: 


$$
\operatorname{Cov}\left[z\left(x^{i}\right), z\left(x^{j}\right)\right]=\exp \left[-d\left(x^{i}, x^{j}\right)\right]
$$

The Kriging model at a specific point is expressed as:

$$
y(x)=u^{\prime}+r^{\prime}(x) R^{-1}\left(y-1 u^{\prime}\right)
$$

where $y=\left[y\left(x^{(1)}\right), y\left(x^{(2)}\right), \ldots, y\left(x^{(N)}\right)\right]^{\mathrm{T}} . R$ is the $n \times n$ correlated matrix. $u^{\prime}$ is the approximate value of $u . r$ is the vector of the $i_{t h}$ element.

The correlation factor is computed as:

$$
\ln \left(u^{\prime}, \hat{\sigma}^{2}, \theta\right)=-\frac{n}{2} \ln (2 \pi)-\frac{n}{2} \ln \left(\hat{\sigma}^{2}\right)-\frac{1}{2} \ln (|R|)-\frac{1}{2 \hat{\sigma}^{2}}\left(f-1 u^{\prime}\right)^{\prime} R^{-1}\left(f-1 u^{\prime}\right)
$$

The values of the $u^{\prime}$ and $\hat{\sigma}^{2}$ at the specific $\theta_{k}$ are defined as:

$$
\begin{gathered}
u^{\prime}=\frac{1^{T} R^{-1} f}{1^{T} R^{-1} f} \\
\hat{\sigma}^{2}=\frac{(f-1 \hat{u})^{T} R^{-1}(f-1 \hat{u})}{N}
\end{gathered}
$$

To minimise the predictive deviation, the additional data in the interesting region (e.g. Pareto set) are employed to learn, train, and rebuild the Kriging model. The convergence tolerance $\varepsilon$ without considering the magnitudes of the objectives is determined as:

$$
M A E_{r}=\max \left|\frac{y_{i}-y_{\text {pred }}}{y_{i}}\right|<\varepsilon
$$

where $\mathrm{MAE}_{\mathrm{r}}$ is the relatively max absolute error. $y_{i}$ and $y_{\text {pred }}$ present the experimental and predicted values.

The significance of the Kriging model can be investigated using the normalized root mean squared error (NRSME) [24]. The NRSME value is computed as:

$$
\text { NRMSE }=\frac{\sqrt{\sum_{i=1}^{n}\left(y_{i}-y_{\text {pred }}\right)^{2}}}{\max \left(y_{i}\right)-\min \left(y_{i}\right)}
$$

Step 3: Optimal machining conditions are obtained using the desirability approach.

In this study, each machining performances is transformed to a desirability function $d_{i}$ $\left(0 \leq d_{i} \leq 1\right)[25]$.

For the maximising purpose, the $d_{i}$ is calculated as:

$$
d_{i}=\left\{\begin{array}{c}
0, Y_{i} \leq L_{i} \\
\left(\frac{Y_{i}-L_{i}}{H_{i}-L_{i}}\right)^{w}, L_{i}<Y_{i}<-H_{i} \\
1, \mathrm{Y}_{i} \geq H_{i}
\end{array}\right.
$$

For the mimimising purpose, the $d_{i}$ is calculated as: 


$$
d_{i}=\left\{\begin{array}{c}
0, Y_{i} \leq L_{i} \\
\left(\frac{H_{i}-Y_{i}}{H_{i}-L_{i}}\right)^{w}, L_{i}<Y_{i}<-H_{i} \\
1, Y_{i} \geq H_{i}
\end{array}\right.
$$

For the aimed purpose, the $d_{i}$ is calculated as:

$$
d_{i}=\left\{\begin{array}{l}
\left(\frac{Y_{i}-L_{i}}{T_{i}-L_{i}}\right)^{w 1}, L_{i}<Y_{i}<T_{i} \\
\left(\frac{Y_{i}-H_{i}}{T_{i}-H_{i}}\right)^{w 2}, T_{i}<Y_{i}<H_{i} \\
0, \text { otherwise }
\end{array}\right.
$$

For the range, the $d_{i}$ is calculated as:

$$
d_{i}=\left\{\begin{array}{l}
1, L_{i}<Y_{i}<H_{i} \\
0, \text { otherwise }
\end{array}\right.
$$

where $L_{i}, H_{i}, T_{i}$, and $w_{i}$ presents the low value, the high value, the targeted performance, and the assigned weight, respectively.

For each performance, the desirability value (D) is calculated as:

$$
D=\left(\begin{array}{c}
m \\
\Pi d_{i}^{r_{i}} \\
i=1
\end{array}\right)^{1 / \sum r_{i}}
$$

where $m$ presents number of the machining responses of the CATB process.

The highest desirability value is employed to select the optimal solution.

\section{Experiments and measurements}

The turning-burnishing experiments are conducted on an NC lathe machine labeled EMCOMAT-20D (Fig. 7). The turning and burnishing operations are simultaneously performed on the workpiece. The experimental trials are conducted under the dry conditions.

The aluminum alloy labeled 6061 with a diameter of $40 \mathrm{~mm}$ is used for all trials. The chemical compositions and mechanical properties are shown in Tables 2 and 3, respectively. The pre-machined surface is turned with the depth of cut of $2.0 \mathrm{~mm}$, the feed rate of 0.3 $\mathrm{mm} / \mathrm{rev}$, and the cutting speed of $90 \mathrm{~m} / \mathrm{min}$, respectively. The initial surface roughness is 2.06 $\mu \mathrm{m}$.

A power meter labeled C.A.8333 produced Chauvin Arnoux is used to analyse the energy consumed of the three-phase networks. The total power consumed of the CNC lathe machine is automatically recorded during machining. The electrical clamps are directly connected to the electric power and power lines of the machine. The energy analyser is turned 
on to capture the power variety in the processing time. The interval of $0.1 \mathrm{sec}$. is used to enhance the accuracy of the obtained data. The captured power is stored on the memory card and displayed on the software.

A roughness tester labeled Mitutoyo SJ-301 is used to capture the roughness according to the ISO 4287 standard. The roughness values are measured on five different points on the circular cross-section of the machined sample. The diamond tip of $5 \mu \mathrm{m}$ radius is used to measure on the axial direction. The measured length of $3 \mathrm{~mm}$ is used for each machining segment. The measured ranges of $0.05-40 \mathrm{~mm}$ and the resolution of $0.01 \mathrm{~mm}$ are employed to enhance the accuracy.

A hardness tester labeled HV-112 is used to measure the surface hardness. The hardness values are measured on five different points on the workpiece surface. The diamond indenter is compressed on the treated sample. The test load of $49.03 \mathrm{~N}$ and a dwell time of 5 sec. are employed in all machined workpieces.

\section{Results and Discussions}

\subsection{Development of performance models}

The regression model of the required operational power is shown in Table 4. The values of the coefficient determinations, including the $\mathrm{R}^{2}$, the adjusted $\mathrm{R}^{2}$, and the predicted $\mathrm{R}^{2}$ indicated that the fidelity of the proposed models is acceptable. Experimental data of the CATB operation are displayed in Table 5, in which the turning-burnishing power, air power, and the power consumed in turning-burnishing stage are separately presented. The experimental data from 1 to 41 are used to construct the improved Kriging models. The experimental data from 42 to 50 are employed to investigate the precision of the proposed optimisation models.

The NRMSE is used to explore the soundness of the improved Kriging models. The NRMSE values of the $\mathrm{E}_{\mathrm{M}}, \mathrm{SR}$, and VH models are 0.0018, 0.0014, and 0.0011, respectively (Fig. 8). It can be stated that the improved Kriging models significantly presented the analysed data.

Fig. 9 depicts comparisons between the predicted and experimental values. It can be stated that the high consistency is obtained, and the accuracy of the improved Kriging models is acceptable.

\subsection{Parametric effects}

\subsubsection{The impacts of machining parameters on the turning-burnishing energy}

The consumed energy is a significant indicator to evaluate the environmental impact of the CATB process and the low energy consumption is desirable. The impacts of the varied machining parameters on the energy consumption of the CATB process are shown in Fig. 10. 
Fig. 10a exhibits the effect of the depth of cut and burnishing force on energy consumption. It can be stated that higher turning-burnishing energy is produced with the increased depth of cut and/or burnishing force. When the depth of cut increases, the thickness of the turned chip is increased due to the increment in the contact area between the turning insert and the workpiece. More material processed results in larger plastic deformation, leading to the greater resistance. As a result, a higher power is required to overcome the resistance, and the energy consumption increases. When the burnishing force increases, the burnished pressure increases. There is a higher degree of plastic deformation and resistance. A higher power for the spindle system is required to overcome the resistance and to remove the materials during the machining process; hence, the energy consumption increases accordingly.

Fig. 10b exhibits the impacts of the feed rate and the machining speed on the energy consumption. As a result, an increased feed rate and/or speed causes a reduction in the energy consumption. When the feed rate increases, the higher momentum of the spindle system is produced, leading to the higher machining power. A higher feed rate may cause the workhardening on the machined sample, which requires the higher machining power due to the greater resistance. Fortunately, an increased feed rate leads to a reduction in the turningburnishing time, resulting in a reduction in the energy consumption. Moreover, a higher spindle motor torque is produced when the speed is increased. Fortunately, the higher speed leads to a reduction in the turning-burnishing time, resulting in a decreased energy consumption. In addition, the higher speed causes an increased machining temperature, which results in a low hardness and strength of the workpiece. Therefore, the lower energy consumption is used for the softer samples.

Fig. 10c exhibits the effect of the ball diameter on the energy consumption. It can be stated that an increased diameter causes a higher energy consumption. As the diameter increases, the machining area between the burnishing ball and the workpiece increases. More material is burnished; the deformation is larger; and the greater resistance and friction are generated. Obviously, the higher power of the spindle system is required to remove the material during the machining process; hence, the higher energy consumption is required.

The parametric contributions of the varied machining parameters on the turningburnishing energy model are exhibited in Fig. 10d. The blue and red bars denote the positive and negative impacts, respectively. The feed rate is the most effective parameter $(29.43 \%)$, followed by the machining speed $(16.31 \%)$, the depth of cut $(4.15 \%)$, the burnishing force $(4.08 \%)$, and the diameter $(3.33 \%)$, respectively. The contributions of the $\mathrm{f}^{2}$ and $\mathrm{V}^{2}$ are $3.54 \%$ and $15.19 \%, 4.69 \%$, respectively. 


\subsubsection{The impacts of machining parameters on the surface roughness}

The roughness is an important evaluator to explore the impact of the CATB process and a low roughness is preferred. Fig. 11 depicted the influences of the varied machining parameters on the surface roughness.

Fig. 11a displays the effects of the depth of cut and the burnishing force on the surface roughness. It can be stated that the higher roughness is produced with an increased depth of cut. When the depth of cut increases, the machining area between the turning insert and the machined sample increases. The bigger chip is heavily detached from the machined sample; leading to increased surface roughness. In contrast, the roughness is decreased with an increased burnishing force. The increment in the burnishing force causes the higher burnished pressure, which increases the plastic deformation. More material is compressed and the roughness is therefore decreased.

Fig. $11 \mathrm{~b}$ exhibits the effect of the feed rate and the speed on the surface roughness. It can be stated that the roughness is decreased at a higher speed. The vibration of the machine tool may be suppressed at an increased speed, leading to machining stability. Moreover, an increased speed causes higher machining temperature, which leads to a reduction in hardness and strength. For the turning, the chip is easily detached from the workpiece. For the burnishing, the material is smoothly burnished; hence, a low roughness is obtained.

A low feed rate causes a small distance between the successively turned or burnished paths, leading to a low surface roughness. A higher feed rate causes an increased distance between the turned or burnished peaks. Therefore, the higher feed mark is left on the machined sample and the coarse surface is generated. When the feed rate increases, the turning and burnishing forces increase, resulting in the machining instability; hence, the higher surface roughness is produced.

The influence of the ball diameter on the surface roughness is shown in Fig. 11c. It can be stated that low roughness is obtained with an increased diameter. When the ball diameter increases, the machining length between the turned surface and the compressing ball is decreased, leading to the smaller peaks; hence, the surface roughness is reduced.

The parametric contributions of the varied machining parameters on the surface roughness model are exhibited in Fig. 11d. The feed rate is the most effective parameter (24.89\%), followed by the burnishing force (24.21\%), depth of cut (23.02\%), machining speed $(16.82 \%)$, and ball diameter $(6.83 \%)$, respectively. The contribution of the $\mathrm{f}^{2}$ and $\mathrm{V}^{2}$ are $1.15 \%$ and $0.17 \%$, respectively. 
The burnished images at the different processing inputs are depicted in Fig. 12. The grooves and holes are produced on the turned surface. Fortunately, these faults are removed on the treated surface with the aid of the CATB process.

\subsubsection{The impacts of machining parameters on the Vicker hardness}

The surface hardness is another evaluator to explore the impact of the CATB process and the high surface hardness is preferred. Fig. 13 depicted the influences of the varied machining parameters on the Vicker hardness of the machined surface.

Fig. 13a exhibits the effect of the depth of cut and the burnishing force on the Vicker hardness of the machined surface. It can be stated that the higher hardness is associated with the increment in the depth of cut and/or the burnishing force. Moreover, a further depth of cut causes a reduction in the surface hardness. An increased depth of cut causes a larger degree of work-hardening, resulting in an improved hardness. However, a further depth of cut leads to high machining temperature, which may relieve the residual stress; hence, the hardness is decreased. When a burnishing force increases, a higher degree of plastic deformation is produced. More material is compressed and burnished; hence, the higher hardness is obtained.

Fig. 13b exhibits the effect of the feed rate and machining speed on the hardness. It can be stated that higher hardness is obtained with an increased feed rate and/or speed. Further feed rate causes a reduction in the hardness. An increased feed rate causes a higher degree of the work-hardening on the machined surface, resulting in enhanced hardness. A further feed rate leads to high machining temperature, which may relieve the residual stress; hence, the hardness is decreased. Higher machining speed causes increased machining temperature, resulting in an improved plastic deformation. The work-hardening behavior on the machined surface is produced; hence, the hardness is improved.

Fig. 13c exhibits the effect of the ball diameter on the hardness. At a low diameter, the higher burnishing pressure is generated, which causes the higher hardness. An increased diameter causes an increment in the machining area between the ball and the workpiece, which decreases the burnishing pressure; hence, the hardness is decreased.

The parametric contributions of the varied machining parameters on the roughness model are exhibited in Fig. 12d. The depth of cut is the most effective parameter (14.14\%), followed by the burnishing force (13.97\%), the depth of cut $(13.59 \%)$, the speed $(11.62 \%)$, and the diameter $(7.40 \%)$, respectively. The contribution of the $\mathrm{f}^{2}, \mathrm{a}^{2}, \mathrm{~V}^{2}, \mathrm{D}^{2}$, and $\mathrm{BF}^{2}$ are $6.90 \%, 5.12 \%, 2.67 \%, 1.84 \%$, and $1.36 \%$, respectively.

\subsection{Optimisation results}

In this study, the developed models are employed to obtain the optimal machining parameters for improvements of the turning-burnishing energy and machining quality. To 
solve the multi-objective optimisation that minimises the energy consumtion as well as the surface roughness and enhances the surface hardness, the desirability approach is utilised to predict the optimal machining parameters. Fig. 14 illustrates the ramp graphs of optimal machining parameters with the aid of the DA. The selected values for the depth of cut, the burnishing force, the diameter, the feed rate, and the machining speed are $0.66 \mathrm{~mm}, 196.3 \mathrm{~N}$, $8 \mathrm{~mm}, 0.112 \mathrm{~mm} / \mathrm{rev}$, and $110 \mathrm{~m} / \mathrm{min}$, respectively. The optimal values of the $\mathrm{E}_{\mathrm{M}}, \mathrm{SR}$, and $\mathrm{VH}$ are $12.00 \mathrm{~kJ}, 0.18 \mu \mathrm{m}$, and $239 \mathrm{HV}$. At the optimal point, the turning-burnishing energy and roughness are decreased by $20.15 \%$ and $65.38 \%$, respectively, while the hardness is enhanced by $30.05 \%$, as compared to the common setting values (Table 6).

A confirmatory trial is employed at the selected point to explore the strength of the proposed approach. The comparison findings are shown in Table 7. The prediction errors of the $\mathrm{E}_{\mathrm{M}}, \mathrm{SR}$, and $\mathrm{VH}$ are $2.00 \%, 5.56 \%$, and $0.42 \%$, respectively. The small values of the errors reveal a good correlation between the optimized and experimental data. Therefore, the precision of the developed approach is acceptable for the optimisation of the CATB process.

\subsection{Evaluation of the production costs}

The whole cost model of the CATB operation (CB) is expressed as:

$$
C B=C_{T B M}+C_{E}+C_{C H}+C_{T}
$$

where $\mathrm{C}_{\mathrm{TBM}}, \mathrm{C}_{\mathrm{E}}, \mathrm{C}_{\mathrm{CH}}$, and $\mathrm{C}_{\mathrm{TB}}$ present the turning-burnishing, energy, tool change, and tool costs, respectively.

The total time of the CATB operation is calculated as:

$$
t_{\text {total }}=t_{o}+t_{s t}+t_{\text {air }}+t_{c h}+t_{T B}
$$

where $t_{0}, t_{s t}, t_{a i r}$, and $t_{c h}$ denotes the start-up, setup, air-turning, $t$ tool change times, respectively.

The turning-burnishing cost $\left(\mathrm{C}_{\mathrm{TBM}}\right)$, the energy cost $\left(\mathrm{C}_{\mathrm{E}}\right)$, the tool changing cost $\left(\mathrm{C}_{\mathrm{CH}}\right)$, and the tool cost $\left(\mathrm{C}_{\mathrm{T}}\right)$ are calculated using Eqs. (22-26):

$$
\begin{gathered}
C_{T B M}=x\left(t_{o}+t_{s t}+t_{a i r}+t_{c h}+t_{T B}\right) \\
C_{E}=x_{e}\left(\mathrm{P}_{o} t_{o}+P_{s t} t_{s t}+P_{a i r} t_{a i r}+P_{s t} t_{c h}\left(\frac{t_{T B}}{T_{T}}+\frac{t_{T B}}{T_{B}}\right)+P_{T B} t_{T B}\right) \\
C_{C H}=x \mathrm{t}_{c h}\left(\frac{t_{T B}}{T_{T}}+\frac{t_{T B}}{T_{B}}\right) \\
C_{T}=y_{c}\left(\frac{t_{T B}}{T_{T}}+\frac{t_{T B}}{T_{B}}\right) \\
T_{T}=\frac{c^{\alpha} \times 60}{V^{\alpha} f^{\beta}}
\end{gathered}
$$


where $\mathrm{x}$ denotes the comprehensive cost of the machine, labor, and management (VND/s). $\mathrm{x}_{\mathrm{e}}$ presents the energy cost per hour (VND/kWh). $\mathrm{y}_{\mathrm{c}}$ presents the cost of fabricated turningburnishing tool ( $\mathrm{VND} /$ piece). $\mathrm{T}_{\mathrm{T}}$ and $\mathrm{T}_{\mathrm{B}}$ are the tool life of the turning insert and the compressing ball, respectively. The coefficients of the cost model are exhibited in Table 8. It is resulted that the total cost is decreased by $17.19 \%$ (Table 9).

\section{Conclusions}

In this study, the compressed air assisted-turning-burnishing (CATB) process was successfully developed to enhance the productivity of machining operations of aluminum alloys. A novel turning-burnishing tool was designed and made to perform the experiments. The parameter based-optimisation of the CATB process that saves the energy used as well as surface roughness and enhances the Vicker hardness. The relations between the varied machining parameters and the machining responses of the CATB process were constructed with the support of the improved Kriging models. The desirability approach was applied to identify the optimum parameters for the machining process. The key findings and contributions of a study are listed as follows:

1. The Kriging-based models for the turning-burnishing energy, the surface roughness, and the Vicker hardness of the machined surface have the NRMSE values of 0.0018, 0.0014, and 0.0011 , respectively, indicating the soundness and reliability of the model. The improved Kriging correlations of the performances of the CATB process showed that a high accuracy is obtained for the predictive purposes. The modeling technique can be considered as a powerful solution to depict the nonlinear approximations of measurements for the machining process.

2. The highest values of the speed and feed rate can be used to obtain the low energy consumption, while the lowest levels of the depth of cut, burnishing force, and diameter cause a decrease in the energy consumption. The low values of the depth of cut and the feed rate are recommended to decrease the surface roughness. The highest levels of the speed, burnishing force, and diameter can be used to get a smoother surface. The improved hardness is achieved at the high speed and/or burnishing force; and a small ball diameter is used to obtain the enhanced hardness. The middle values of the depth of cut and the feed rate can be applied to improve the surface hardness.

3. The statistical analysis of the energy consumption model indicated that the feed rate is the most effective parameter $(29.43 \%)$, followed by the machining speed $(16.31 \%)$, depth of cut $(4.15 \%)$, burnishing force $(4.08 \%)$, and diameter $(3.33 \%)$, respectively.

4. For the surface roughness model, the feed rate has the highest contribution (24.89\%), followed by the burnishing force, depth of cut, machining speed, and ball diameter with the contributions of $24.21 \%, 23.02 \%, 16.82 \%$, and $6.83 \%$, respectively. 
5. For the Vicker hardness model, the depth of cut is the most effective parameter (14.14\%), followed by the burnishing force (13.97\%), depth of cut (13.59\%), speed (11.62\%), and diameter $(7.40 \%)$, respectively.

6. As a result, the optimal outcomes of the depth of cut, burnishing force, diameter, feed rate, and speed are $0.66 \mathrm{~mm}, 196.3 \mathrm{~N}, 8 \mathrm{~mm}, 0.112 \mathrm{~mm} / \mathrm{rev}$, and $110 \mathrm{~m} / \mathrm{min}$. Energy cosnumed and suface roughness are decreased by $20.15 \%$ and $65.38 \%$, while the hardness is enhanced by $30.60 \%$. The comprehensive cost is decreased by $17.19 \%$ at the optimal solution.

7. The optimal finding significantly improves in energy consumption, surface properties, and production costs. The obtained results can be used as an effective solution to achieve the sustainable production for the turning-burnishing process. Moreover, the outcome can be employed for the knowledge-based system for the hybrid machining process.

8. The combined turning and burnishing process is considered as the effective solution to enhance both machining quality and productivity. The successfully developed turningburnishing tool in this study has potentials for industrial applications, especially it can be directly applied to machining operations of cylindrical workpieces for various non-ferrous metals, such as aluminum, copper, and brass. Moreover, the hybrid tool is referred as a design pattern to develop efficiently machining devices which have additional burnishing heads or employ hydraulic actuators.

9. The hybrid approach including the improved Kriging model and DA can extensively support the optimisation of the hybrid machining process, in which optimal objectives have contradictory impacts. Moreover, this scientific approach gives a reliable optimal solution, as compared to using the practical experience of the machine operator.

Finally, this work addressed the three machining responses including the $\mathrm{E}_{\mathrm{M}}, \mathrm{SR}$, and VH that were considered as the outputs. Other responses such as residual stress and the depth of the hardened layer should be studied in order to holistically optimise the CATB process.

\section{ACKNOWLEDGMENT}

This research is funded by Vietnam National Foundation for Science and Technology Development (NAFOSTED) under grant number 107.04-2020.02.

\section{Declaration of conflicting interests}

The author(s) declared no potential conflicts of interest with respect to the research, authorship, and/or publication of this article. 


\section{Nomenclature}

$\begin{array}{cl}a & \text { Depth of cut } \\ v & \text { Machining speed } \\ f & \text { Feed rate } \\ B F & \text { Burnishing force } \\ D & \text { Ball diameter } \\ \text { AHP } & \text { Analytic hierarchy process } \\ \text { ANN } & \text { Artificial neural network } \\ \text { ANFIS } & \text { Adaptive neuro-fuzzy inference system } \\ \text { ASA } & \text { Adaptive simulated annealing } \\ \mathrm{BD} & \text { Bonding strength } \\ \mathrm{CS} & \text { Compressive stress } \\ \mathrm{CATB} & \text { Compressed air assisted-turning-burnishing } \\ \mathrm{DA} & \text { Desirability approach } \\ \mathrm{EF} & \text { Energy efficiency } \\ \mathrm{EC} & \text { Energy consumption } \\ \mathrm{GRA} & \text { Grey relation analysis } \\ \mathrm{MT} & \text { Machining temperature } \\ \mathrm{MR} & \text { Machining rate } \\ \mathrm{MH} & \text { Micro-hardness } \\ \mathrm{MQL} & \text { Minimum quantity lubrication } \\ \mathrm{MRR} & \text { Material removal rate } \\ \mathrm{NCCA} & \text { Neighborhood cultivation genetic algorithm } \\ \mathrm{OPS} & \text { Operational safety } \\ p & \text { burnishing pressure } \\ \mathrm{F}_{\mathrm{c}} & \text { Machining force } \\ \mathrm{F}_{\mathrm{z}} & \text { Tangential cutting force } \\ \mathrm{PF} & \text { Power factor } \\ \mathrm{P}_{\mathrm{c}} & \text { Cutting power } \\ \mathrm{PC} & \text { Porosity content } \\ \mathrm{RSM} & \text { Response surface method } \\ \mathrm{R}_{\mathrm{a}} & \text { Arithmetical mean roughness } \\ \mathrm{R}_{\mathrm{z}} & \text { Means roughness depth } \\ r & \text { Nose radius } \\ S & \text { Spindle speed } \\ S S & \text { Slenderness of shaft } \\ \mathrm{T}_{\mathrm{c}} & \text { Turning cost } \\ \mathrm{T}_{\text {total }} & \text { Total machining time } \\ \mathrm{TH} & \text { Tool life } \\ \alpha & \text { Inclination angle } \\ & \end{array}$




\section{REFERENCES}

1. Warsi SS, Jaffery S.H.I, Ahmad R, et al. Development of energy consumption map for orthogonal machining of Al 6061-T6 alloy. Proc IMechE, Part B: J Engineering Manufacture 2018; 232: 2510-2522.

2. Warsi SS, Jaffery S.H.I, Ahmad R, et al. Development and analysis of energy consumption map for high-speed machining of Al 6061-T6 alloy. Int J Adv Manuf Technol 2018; 96: 91-102.

3. Warsi SS, Agha MH, Ahmad R, et al. Sustainable turning using multi-objective optimisation: a study of Al 6061 T6 at high cutting speeds. Int J Adv Manuf Technol 2019; 100: 843-855.

4. Nguyen TT. Prediction and optimisation of machining energy, surface roughness, and production rate in SKD61 milling. Measurement 2019; 136: 525-544.1

5. Imani L, Rahmani HA, Hamzeloo R, et al. Modeling and optimizing of cutting force and surface roughness in milling process of Inconel 738 using hybrid ANN and GA. Proc IMechE, Part B: J Engineering Manufacture 2020; 234: 920-932.

6. Nguyen TT, Mia M, Dang XP, et al. Green machining for the dry milling process of stainless steel 304. Proc IMechE, Part B: J Engineering Manufacture 2020; 234: 881899.

7. Laouissi A, Yallese MA, Belbah A, et al. Investigation, modeling, and optimisation of cutting parameters in turning of gray cast iron using coated and uncoated silicon nitride ceramic tools based on ANN, RSM, and GA optimisation. Int J Adv Manuf Technol 2019; 101: 523-548.

8. Awale A, and Inamdar K. Multi-objective optimisation of high-speed turning parameters for hardened AISI S7 tool steel using grey relational analysis. J Braz Soc Mech Sci Eng 2020; 42: 356.

9. Nguyen TT. An energy-efficient optimisation of the hard turning using rotary tool. Neural Comput and Applic 2020. https://doi.org/10.1007/s00521-020-05149-2.

10. Nguyen TT, Duong QD, Mia M. Sustainability-Based Optimisation of the Rotary Turning of the Hardened Steel. Metals. 2020, 10: 939.

11. Tong X, Liu X, and Yu S. Support vector regression and genetic-algorithm-based multiobjective optimisation of mesoscopic geometric characteristic parameters of ball-end milling tool. Proc IMechE, Part B: J Engineering Manufacture 2020; 234: 1333-1345. 
12. Alswat HM, Mativenga PT. Extended model for selection of optimum turning conditions based on minimum energy considerations. Proc IMechE, Part B: J Engineering Manufacture 2020. doi:10.1177/0954405420937558.

13. Khan MA, Jaffery SHI, Khan M, et al. Statistical analysis of energy consumption, tool wear and surface roughness in machining of Titanium alloy (Ti-6Al-4V) under dry, wet and cryogenic conditions. Mech Sci 2019; 10: 561-573.

14. Khan MA, Jaffery SHI, Khan M, et al. Sustainability Analysis of Turning Aerospace Alloy Ti-6Al-4V under Dry, Wet and Cryogenic Conditions. In 2020 IEEE 11th International Conference on Mechanical and Intelligent Manufacturing Technologies 2020: 27-30. IEEE.

15. Zhang $\mathrm{P}$ and Liu Z. Effect of sequential turning and burnishing on the surface integrity of Cr-Ni-based stainless steel formed by laser cladding process. Surf Coat Technol 2015; 276: 327-335.

16. Zhang $\mathrm{P}$ and Liu Z. Enhancing surface integrity and corrosion resistance of laser cladded Cr-Ni alloys by hard turning and low plasticity burnishing. Appl Surf Sci 2017: 409: 169178

17. Hua Z, Liu Z, Wang B, Hou X. Surface modification through combination of finish turning with low plasticity burnishing and its effect on fatigue performance for Inconel 718. Surf Coat Technol 2019; 375: 508-517.

18. Przybylski W and Dzionk S. Hybrid Processing by Turning and Burnishing of Machine Components. Advances in Manufacturing. Lecture Notes in Mechanical Engineering 2018. https://doi.org/10.1007/978-3-319-68619-6_56

19. Mezlini S, Mzali S, Sghaier S, et al. Effect of a Combined Machining/Burnishing Tool on the Roughness and Mechanical Properties. Lubr Sci 2014: 26: 175-187.

20. Rami A, Kallel A, Djemaa S, et al. Numerical Assessment of Residual Stresses Induced by Combining Turning-Burnishing (cotub) Process of AISI 4140 Steel using 3D Simulation Based on a Mixed Approach. Int J Adv Manuf Technol 2018: 97: 1897-1912.

21. Rami A, Gharbi, F, Sghaier S, et al. Some Insights on Combined Turning-Burnishing (CoTuB) Process on Workpiece Surface Integrity. Int J Precis Eng Manuf 2018: 19: 6778.

22. Amdoun R, Benyoussef E, Benamghar A, et al. Prediction of hyoscyamine content in Datura stramonium L. hairy roots using different modeling approaches: Response Surface Methodology (RSM), Artificial Neural Network (ANN) and Kriging. Biochem. Eng J 2019; 144: 8-17. 
23. Nguyen TT, Le XB. Optimisation of roller burnishing process using Kriging model to improve surface properties. Proc IMechE, Part B: J Engineering Manufacture 2019; 233: 2264-2282.

24. Li H, Qiu L, Zhang S, Tan J, et al. A surface modeling method for product virtual assembly based on the root mean square of the regional residuals. Proc IMechE, Part B: $J$ Engineering Manufacture 2020; 234: 229-242.

25. Singh RP, Singhal S. An experimental study on rotary ultrasonic machining of Macor ceramic. Proc IMechE, Part B: J Engineering Manufacture 2018; 232: 1221-1234. 


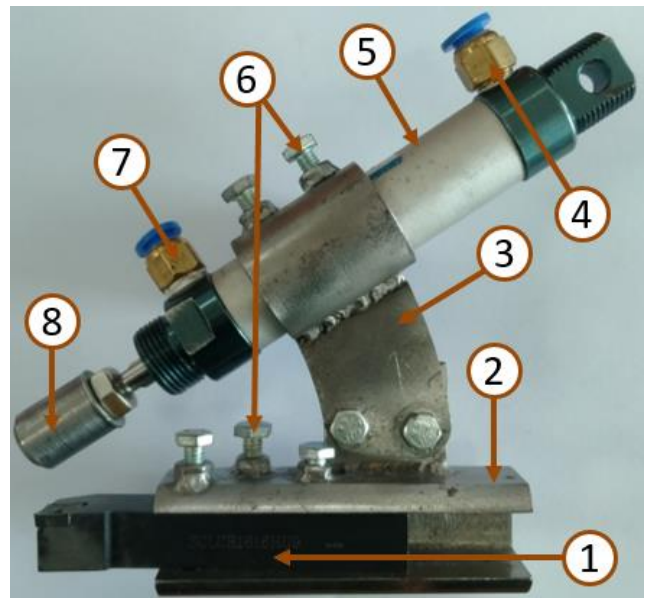

1. Turning tool

2. The base

3. The holder

4. Cap-end port

5. Pneumatic cylinder

6. Position bolt

7. Rod-end port

8. Burnishing head

Figure 1. A new turning-burnishing tool.

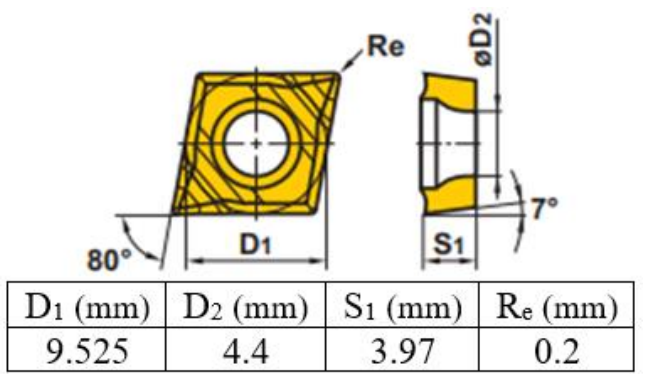

(a)
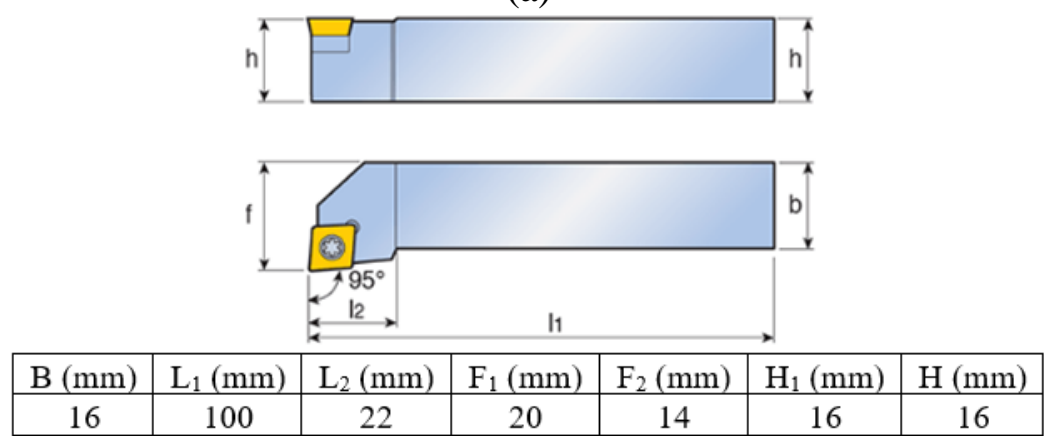

(b)

Figure 2. Technical data of the turning tool: (a) Dimensions of the turning insert, (b) Dimensions of the turning tool shank. 


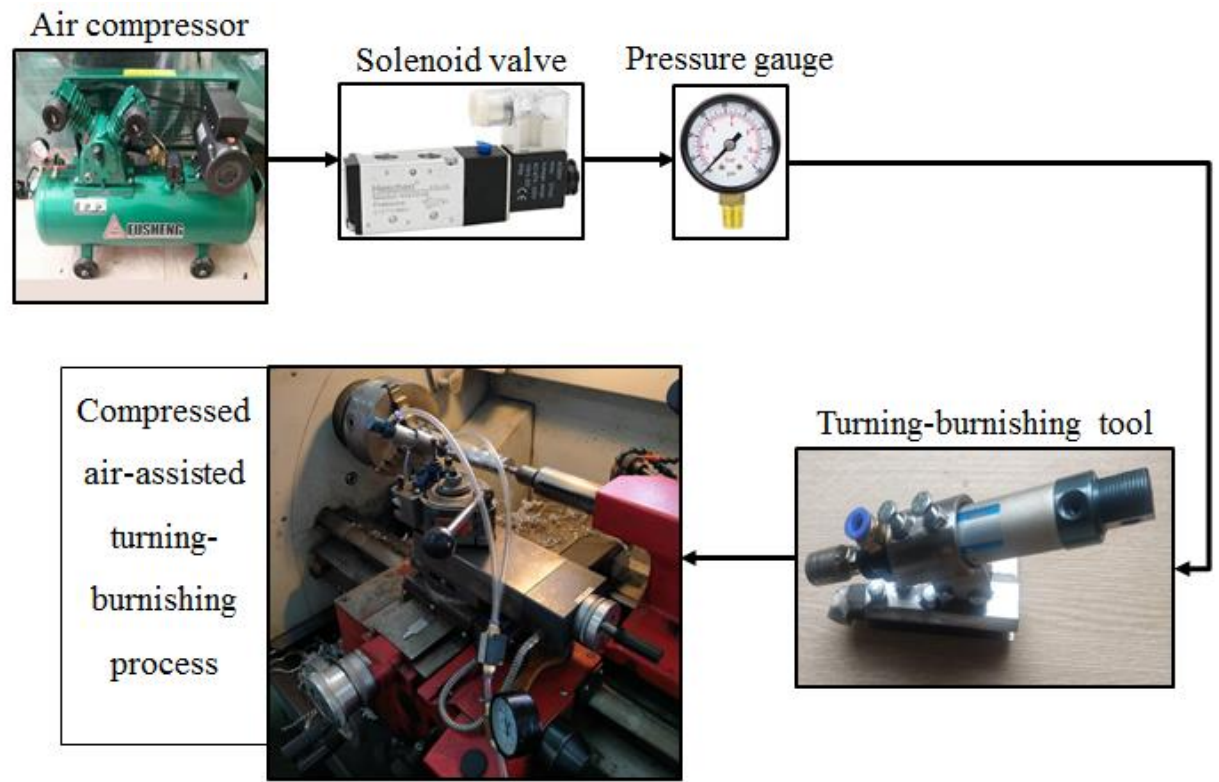

Figure 3. A compressed air assisted-turning-burnishing process.

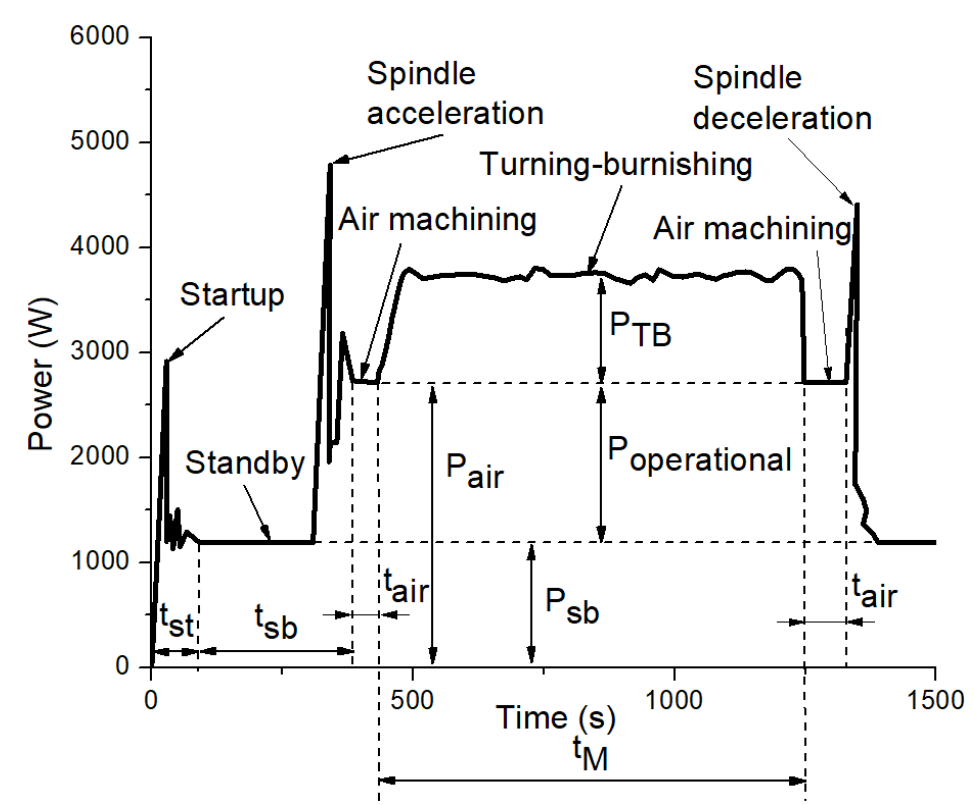

Figure 4. The profile of the power consumption in the CATB process.

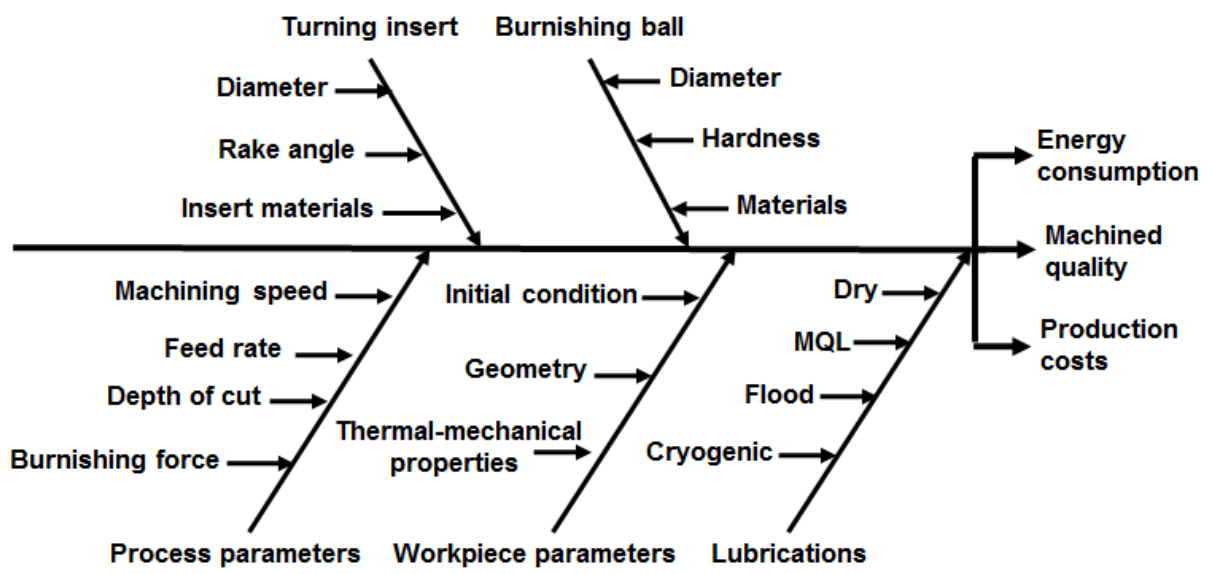

Figure 5. The affecting factors most likely to influence the CATB responses. 


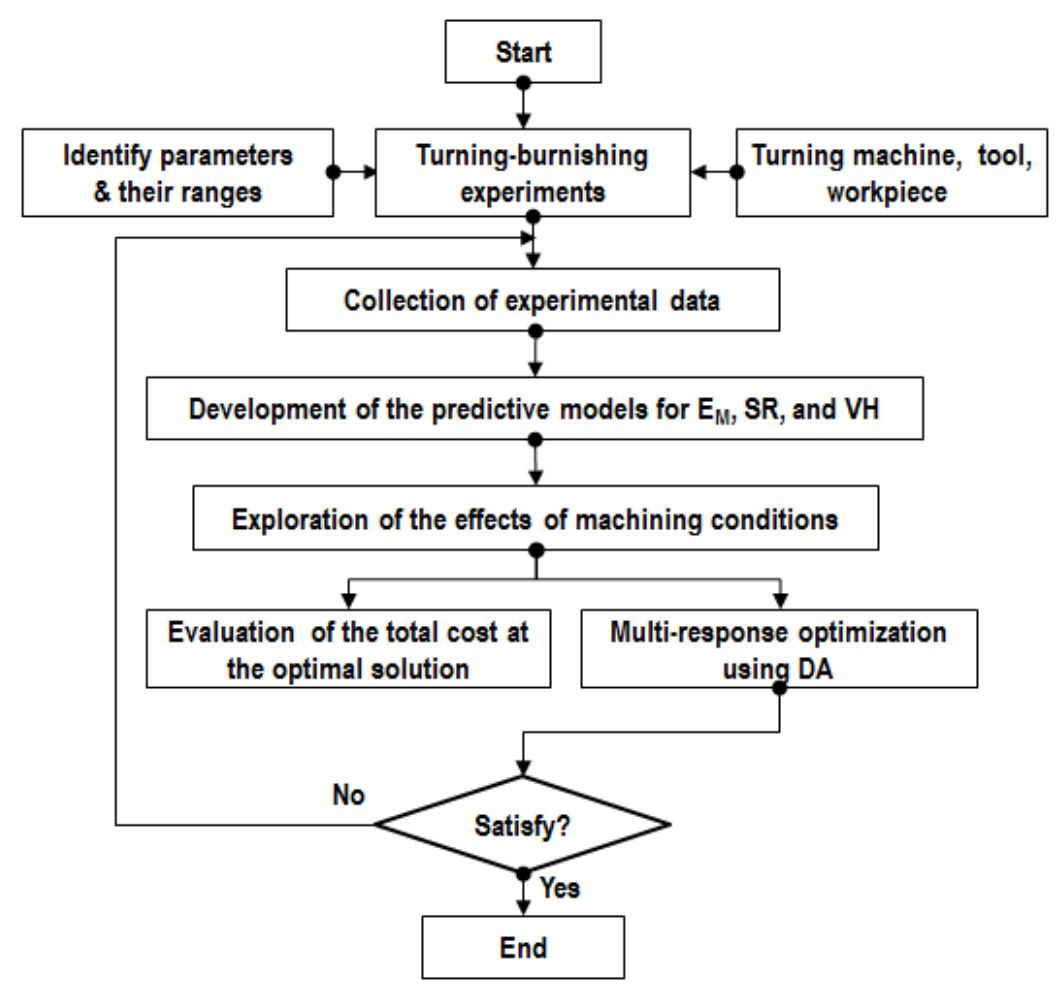

Figure 6. Optimization procedure for the CATB process.

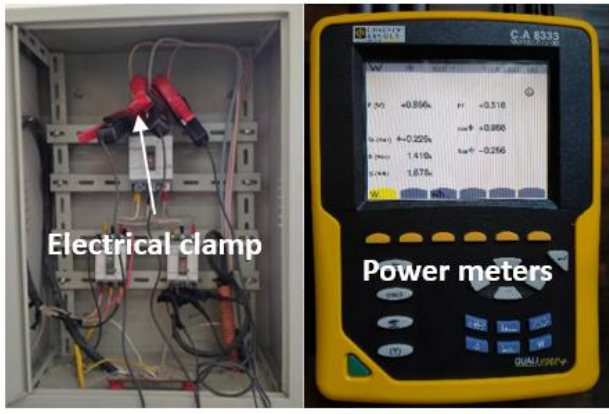

(a)

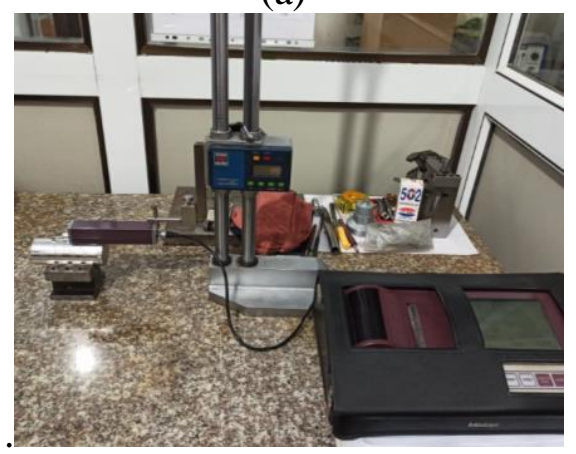

(c)

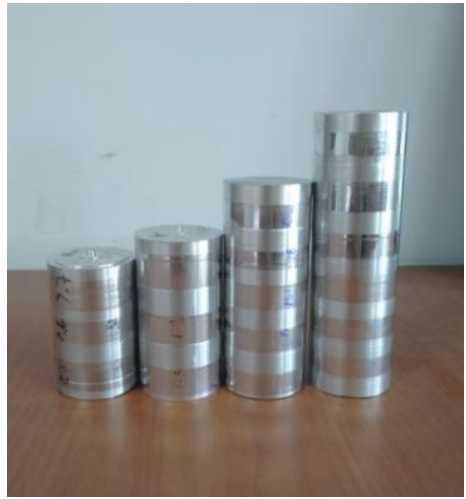

(b)

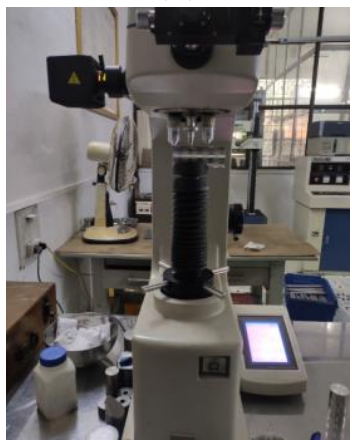

(d)

Figure 7. Experiments and measurement of the CATB performances: (a) Measuring power, (b) Typical samples, (c) Measuring roughnes, (d) Measuring hardness. 


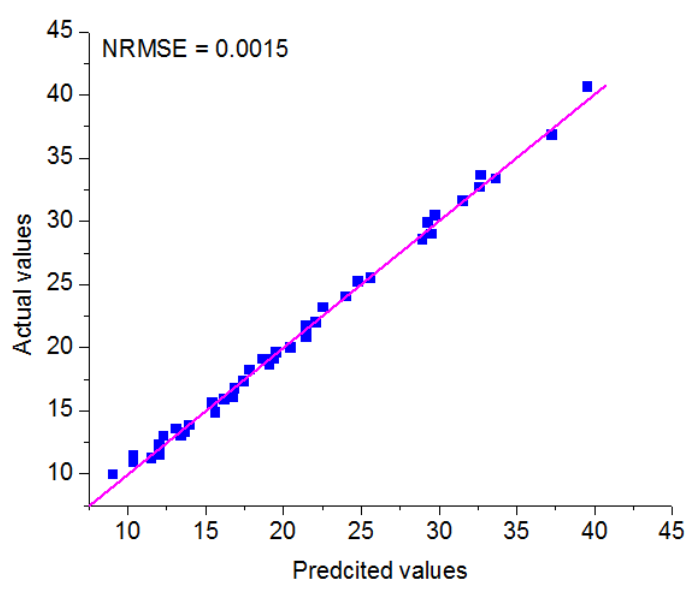

(a)

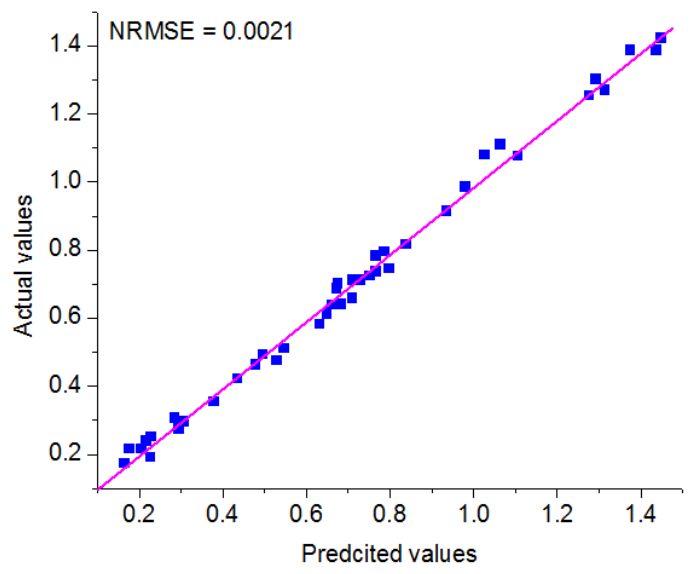

(b)

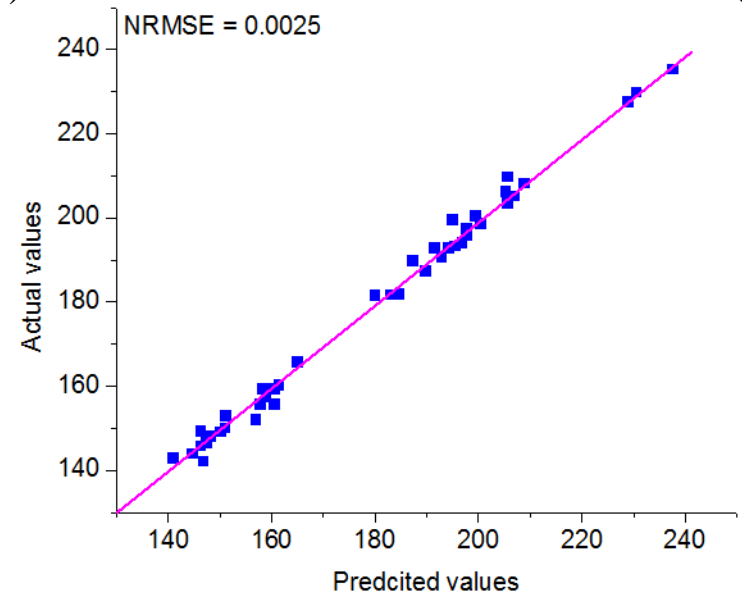

(c)

Figure 8. Investigation of the soundness for performance models: (c) For VH model, (b) For SR model, (c) For VH model. 


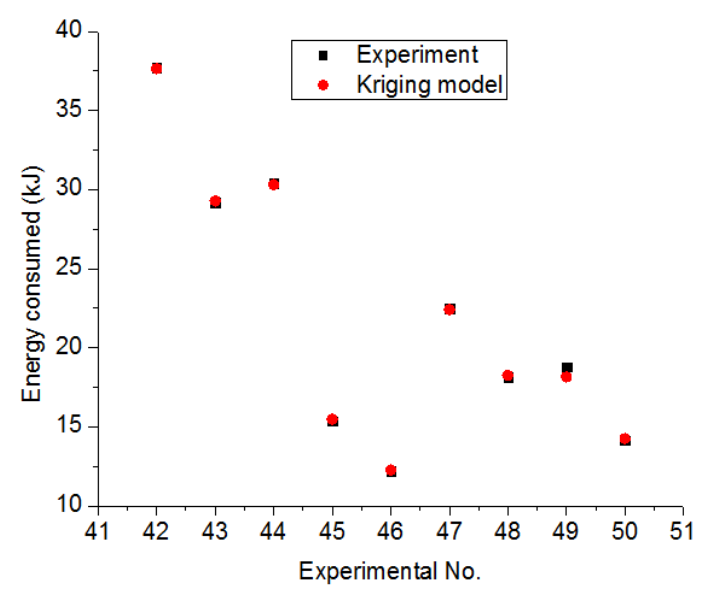

(a)

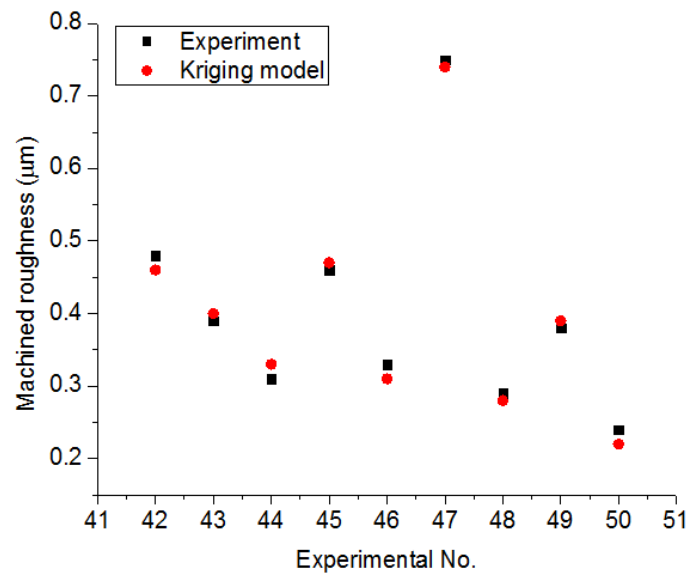

(b)

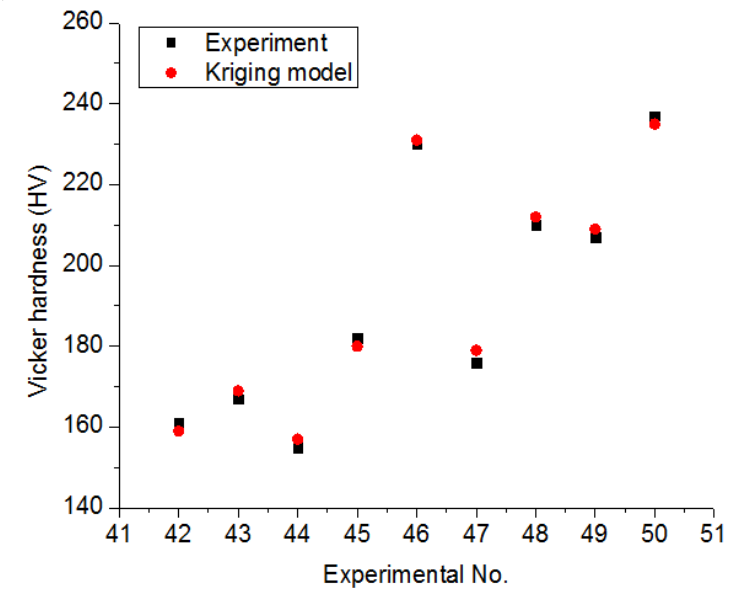

(c)

Figure 9. Exploration of the precision for performance models: (a) For $E_{M}$ model, (b) For SR model, (c) For VH model. 


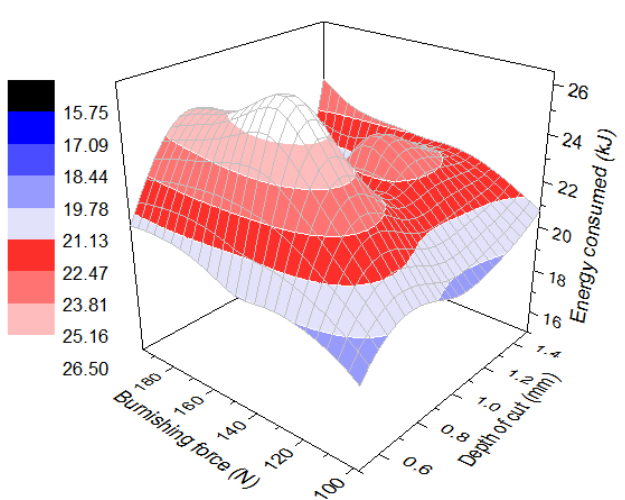

(a)

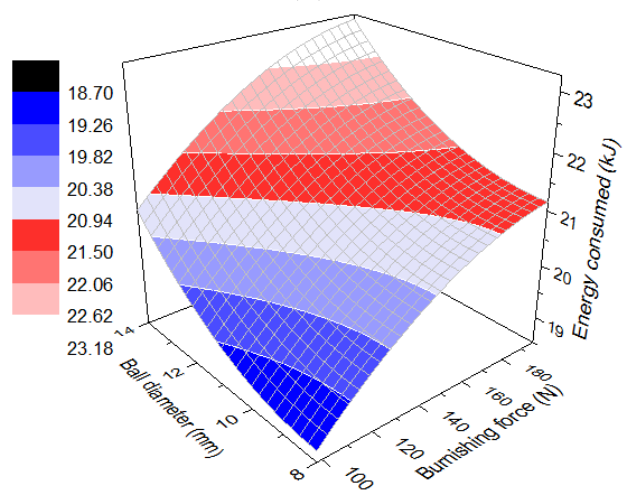

(c)

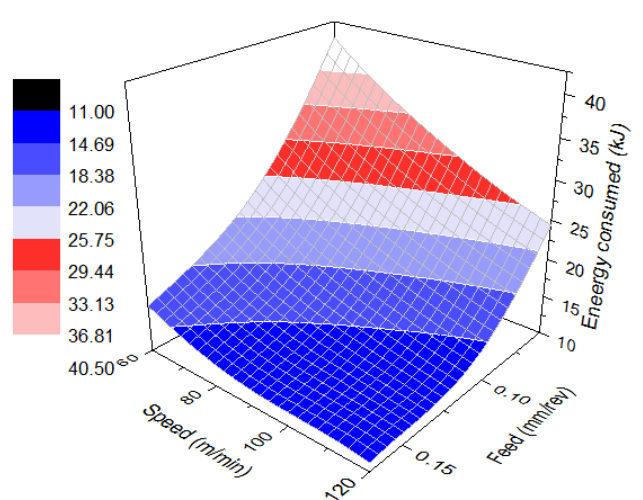

(b)

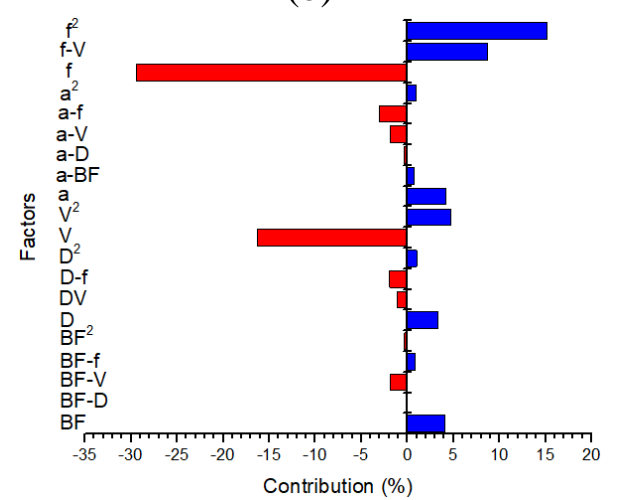

(d)

Figure 10. The impacts of varied machining parameters on the $E_{M}$ model: (a) Energy consumed versus the depth of cut and burnishing force, (b) Energy consumed versus the feed rate and machining speed, (c) Energy consumed versus the ball diameter and burnishing force, (d) Parametric contributions 


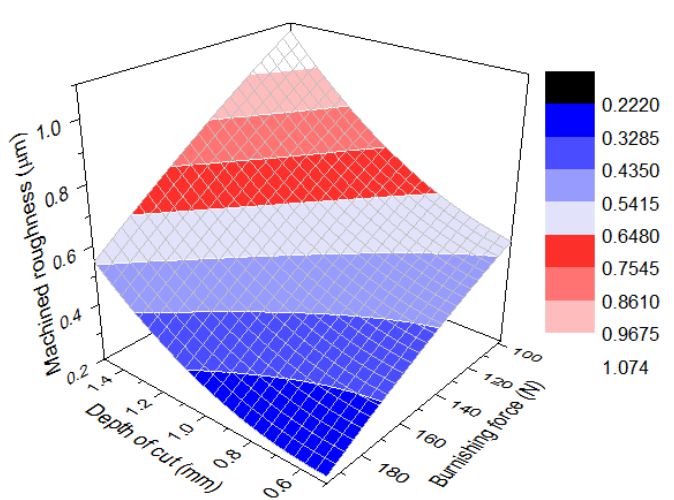

(a)

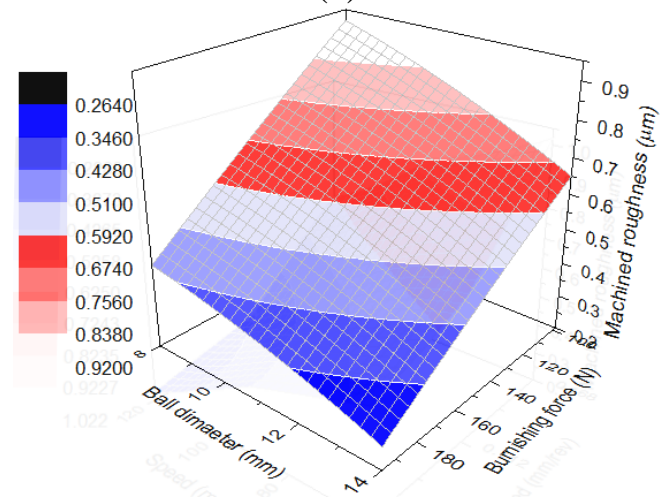

(c)

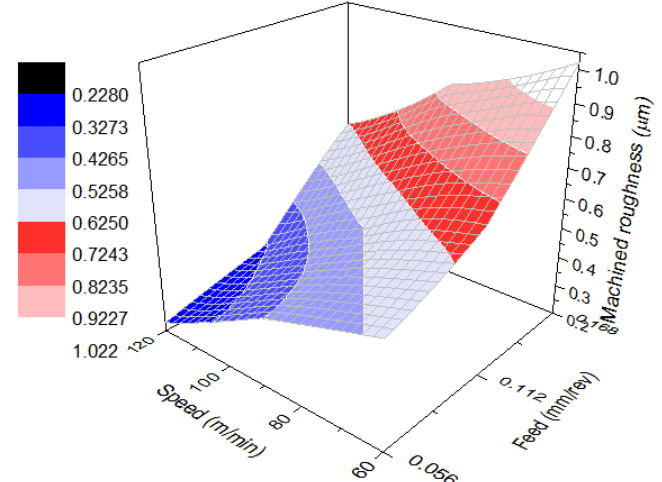

(b)

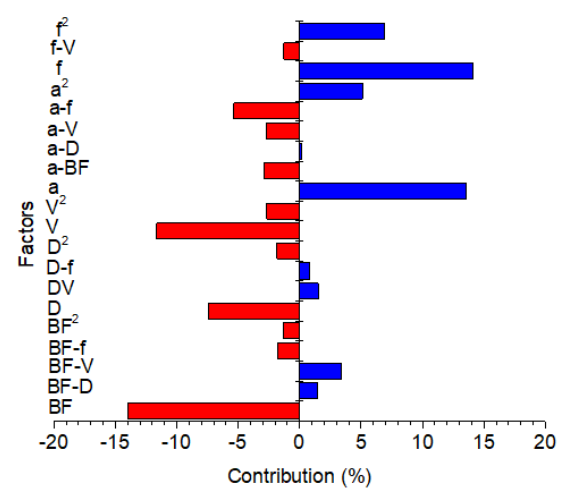

(d)

Figure 11. The impacts of varied varied machining parameters on the SR model: (a) Surface roughness versus the depth of cut and burnishing force, (b) Surface roughness versus the feed rate and machining speed, (c) Surface roughness versus the ball diameter and burnishing force, (d) Parametric contributions

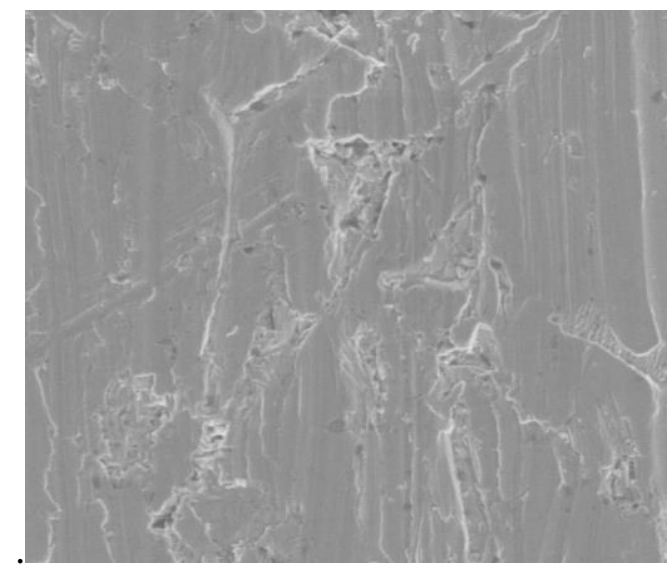

(a)

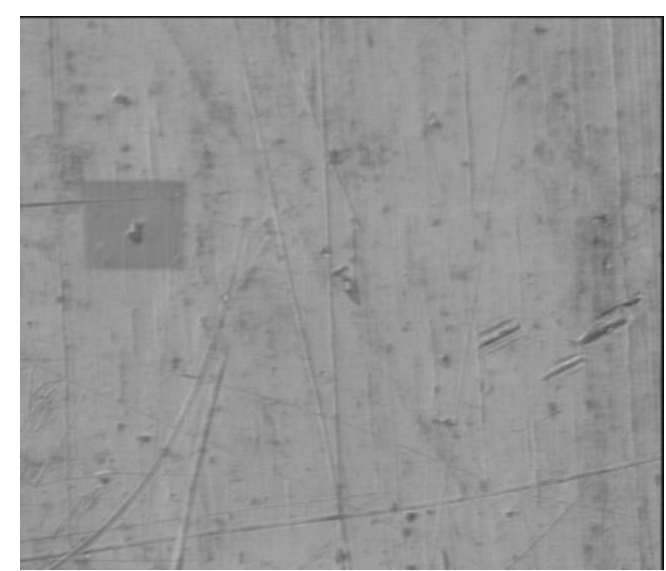

(b)

Figure 12. The surface images at various machining conditions: (a) Turned surface; (b) CATB surface at the experimental No. 10 


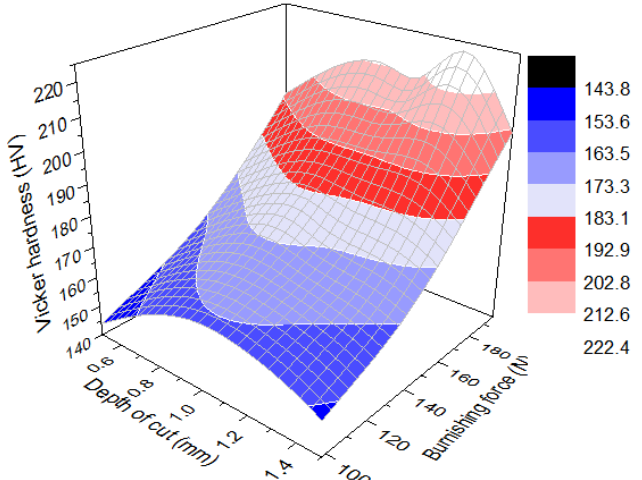

(a)

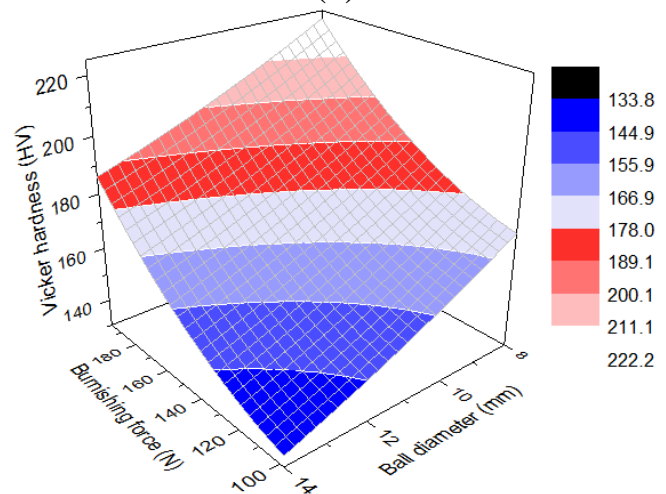

(c)

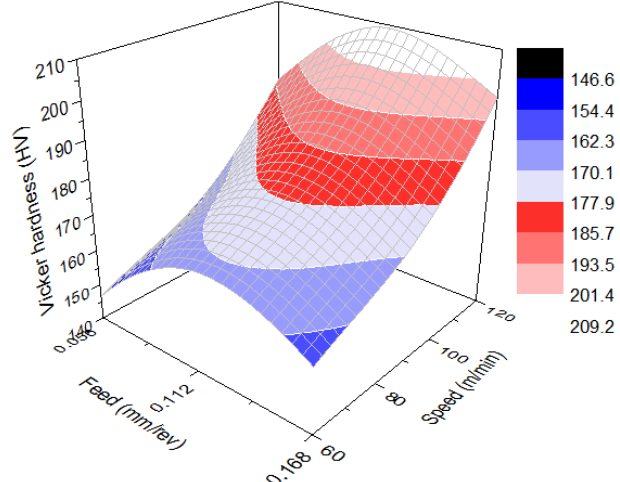

(b)

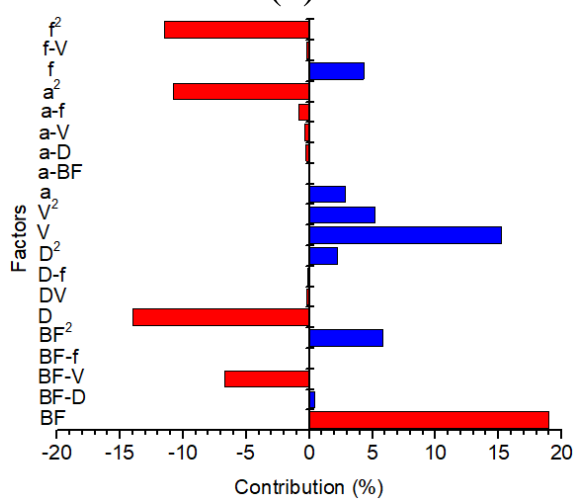

(d)

Figure 13. The impacts of varied varied machining parameters on the VH model: (a) Vicker hardness versus the depth of cut and burnishing force, (b) Vicker hardness versus the feed rate and machining speed, (c) Vicker hardness versus the ball diameter and burnishing force,

(d) Parametric contributions
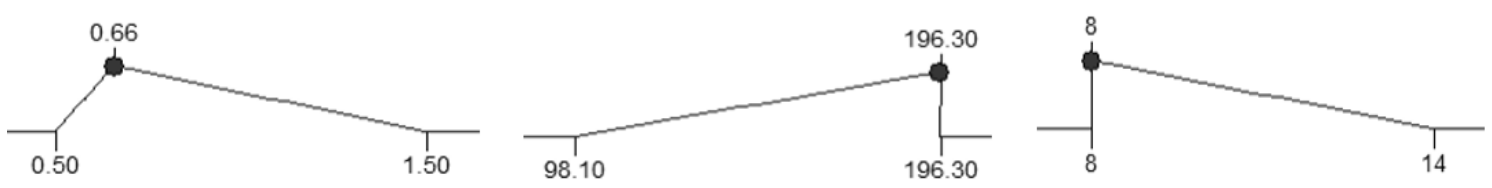

$\mathrm{a}=0.66 \mathrm{~mm}$

$\mathrm{BF}=196.3 \mathrm{~N}$

$\mathrm{D}=8 \mathrm{~mm}$

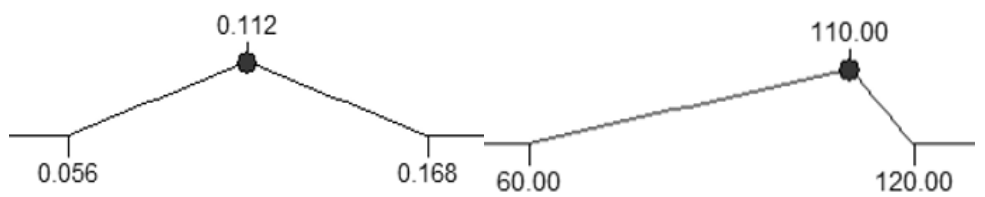

$\mathrm{f}=0.112 \mathrm{~mm} / \mathrm{rev}$.

$\mathrm{v}=110 \mathrm{~m} / \mathrm{min}$

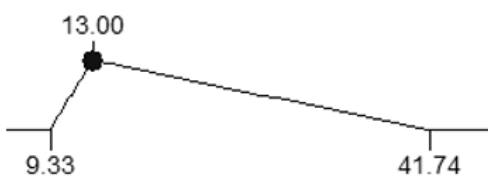

$E_{M}=13.00 \mathrm{~kJ}$

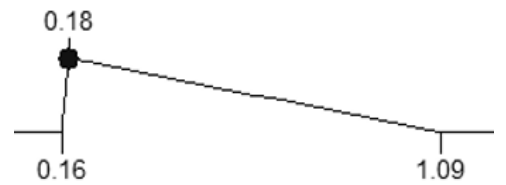

$\mathrm{SR}=0.18 \mu \mathrm{m}$

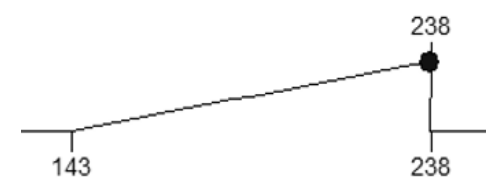

$\mathrm{VH}=238 \mathrm{HV}$

Figure 14. The selection of optimal parameters using the DA 